\title{
O pensamento feminista "amefricano" e a ideia de articulação entre gênero, classe, raça e sexualidade: \\ Ferramentas de análise para a história das sociedades americanas
}

\author{
Bárbara Araújo Machado ${ }^{1}$
}

\begin{abstract}
Resumo: Este artigo aborda diferentes expressões da ideia de que relações de gênero, raça, classe e sexualidade devem ser compreendidas de forma articulada no pensamento feminista "amefricano". Usamos tal conceito em referência à categoria de "amefricanidade" de Lélia Gonzalez, para designar mulheres afrodescendentes nas Américas não apenas no que partilham em termos geográficos, mas também histórico e cultural. Analisando proposições teóricas, metodológicas e políticas de feministas negras norte-americanas, latino-americanas e brasileiras, com foco na historicização das obras de Kimberlé Crenshaw e Lélia Gonzalez, procuramos sublinhar a importância desse pensamento não apenas para a elaboração de reflexões sobre mulheres negras, mas também como ferramenta de análise para a história das sociedades das Américas.
\end{abstract}

Palavras-chave: Feminismo negro; Interseccionalidade; Amefricanidade.

\section{"Amefrican" feminist thought and the idea of articulation between gender, class, race and sexuality: Analytical tools for the history of american societies}

\begin{abstract}
This paper approaches different ways through which "amefrican" feminist thought has defended the ideia that gender, race, class and sexuality must be understood articulately. "Amefrican" will be used as a reference to the concept of "amefricanity" as proposed by Lélia Gonzalez. This concept intends to name women of African descendance in the Americas not only based on the geography aspect, but also on the historical and cultural elements shared by them. The analyzis will focus on theoretical, methodological and political propositions of North-american, Latin and Brazilian black women, focusing in the works of Kimberlé Crenshaw and Lélia Gonzalez. The paper's goal is to stress the importance of this thought not only for researches on Black women, but also as an analytical tool for the history of american societies.
\end{abstract}

Keywords: Black Feminism; Intersectionality; Amefricanity.

Artigo recebido em: 08/05/2019

Artigo aprovado para publicação em: 28/10/2019

\footnotetext{
${ }^{1}$ Doutoranda do Programa de Pós-Gradução em História da Universidade Federal Fluminense. Bolsista Capes. Email: araujombarbara@gmail.com
}

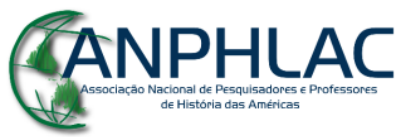


Este artigo aborda diferentes expressões, no pensamento feminista "amefricano", da ideia de que relações de gênero, raça, classe e sexualidade devem ser compreendidas de forma articulada. A categoria de "amefricanidade", elaborada por Lélia Gonzalez, se refere à experiência de afrodescendentes nas "América como um todo (austral, central, insular e setentrional)", designando, para além do caráter geográfico, "todo um processo histórico de intensa dinâmica cultural (resistência, acomodação, reinterpretação, criação de novas formas) referenciada em modelos africanos e que remete à construção de toda uma identidade étnica" (GONZALEZ, 2018f, p. 336). A análise aborda aspectos de proposições teóricas, metodológicas e políticas de feministas negras norte-americanas, latino-americanas e brasileiras, notadamente as obras de Kimberlé Crenshaw e de Lélia Gonzalez, com foco em uma abordagem historicizante de suas proposições. Essa abordagem se dá a partir de um ponto de vista crítico, buscando sublinhar, por um lado, o caráter político e contestador original desse pensamento e por outro, apontá-lo como fonte de ferramentas fundamentais para se pensar a história das sociedades das Américas como um todo, tendo em vista as particularidades das relações sociais engendradas em sua pluralidade de contextos.

A ideia de que é fundamental para pensar as relações de desigualdade social sob mais que um único prisma (apenas de gênero ou apenas racial, por exemplo) tem se tornado cada vez mais estabelecida, não apenas entre os meios intelectuais, mas também nos meios políticos progressistas em geral. ${ }^{2}$ Tal noção tem ganhado terreno dentro e a partir de discussões feministas, trazendo politicamente para o centro do debate a necessidade de pensar "mulheres" no plural, considerando os múltiplos atravessamentos que, articulados ao gênero, produzem subjetividades negras, transgêneras, trabalhadoras

\footnotetext{
${ }^{2}$ Essa é uma discussão muito ampla no campo das humanidades e dar conta de tal amplitude de modo algum é objetivo deste artigo. $\mathrm{O}$ foco recai sobre os primeiros textos em que Kimberlé Crenshaw desenvolve sua argumentação em relação à interseccionalidade e à obra de Lélia González, sob um olhar historicizante. A obra de Gonzalez, por sua vez, tem sido cada vez mais objeto de estudo de acadêmicos brasileiros, e nesse espaço restrito optamos por estabelecer diálogo mais com as obras da autora que com seus comentadores e pesquisadores de sua obra. Para referências nesse sentido, conferir, por exemplo, RATTS, Alex; RIOS, Flávia. Lélia Gonzalez. São Paulo: Selo Negro, 2010; BAIRROS, Luiza. Lembrando Lélia Gonzalez. Afro-Ásia, n. 23, p. 341-361, 2000.
}

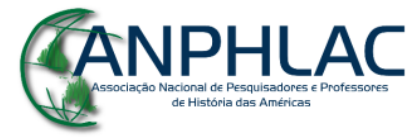


etc. A essa ideia, na política e na academia, se tem chamado "interseccionalidade" ou "feminismo interseccional".

O conceito de interseccionalidade foi cunhado pela jurista norte-americana Kimberlé Crenshaw (1989, 1993) na virada dos anos 1980 para os 1990, mas o entendimento de que gênero, classe, raça e sexualidade devem ser entendidos de maneira articulada remonta aos movimentos de mulheres negras e mulheres de cor $^{3}$ norteamericanas da década de $1970 .{ }^{4}$ O coletivo de mulheres negras Combahee River Colective, em manifesto datado de 1977, já afirmava um compromisso de "lutar contra a opressão racial, sexual, heterossexual e classista", tendo como tarefa "o desenvolvimento de uma análise e uma prática integradas, baseadas no fato de que os maiores sistemas de opressão se encadeiam", configurando uma "síntese dessas opressões [que] criam as condições de nossas vidas." (LA COLECTIVA DEL RIO COMBAHEE, 1988, p. 172, tradução minha).

O feminismo negro teve, portanto, papel primordial no engendramento do que viria a ser sistematizado no conceito de interseccionalidade. Nos anos 1980, obras de autoras negras fundamentais, como Sister outsider, de Audre Lorde, e Feminist Theory: from margin to center, de bell hooks, associavam críticas ao que se convencionou chamar de "feminismo branco" a proposições em torno da necessidade de uma teoria feminista que correspondesse à complexa realidade das experiências vividas por mulheres negras, trabalhadoras, lésbicas etc. (HOOKS, 1984; LORDE, 2007). Em Feminist Theory, hooks denunciou o caráter branco, burguês e liberal que minava o potencial transformador do feminismo, já que o movimento se concentrava predominantemente nas experiências de mulheres brancas privilegiadas, ora consideradas como universais a todas as mulheres, ora como prioritárias (HOOKS, 1984). Com isso em vista, a autora apontou para a "necessidade de desenvolver ideias e análises que englobem um maior número de

\footnotetext{
${ }^{3}$ A expressão "mulheres de cor" aqui é uma tradução de "women of color", usada no contexto norteamericano em referência não apenas a mulheres negras, mas também latinas ou de algum pertencimento étnico não-branco. Há, no mesmo sentido, a expressão "people of color" em referência a populações racializadas de alguma forma.

${ }^{4} \mathrm{O}$ chamado feminismo materialista francês também tem sido considerado como uma matriz teórica pioneira quanto à abordagem da articulação. Essa vertente, contudo, em seus primórdios, buscou articular relações de sexo e classe social, vindo a considerar sistematicamente as relações étnico-raciais posteriormente. Assim, consideramos ainda o feminismo negro norte-americano como precursor, cujo marco localizamos no manifesto do Combahee River Colective.
}

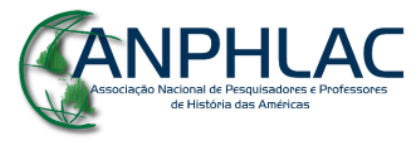


experiências, que sirvam para unificar em vez de polarizar" (HOOKS, 1984, p. x, tradução minha). Reivindicação similar foi feita por Audre Lorde que, em afirmação didática e sintética, concluiu que "não há algo como uma luta envolvendo uma só questão porque nós não vivemos vidas de uma só questão" (LORDE, 2007, p. 139, tradução minha).

Na virada dos anos 1980 para os 1990, Kimberlé Crenshaw sistematizou algumas dessas questões no conceito de interseccionalidade, definido por ela como uma analogia, segundo a qual

\footnotetext{
"vários eixos de poder [...] constituem avenidas que estruturam terrenos sociais, econômicos e políticos. É através delas que as dinâmicas do desempoderamento de movem. [...] Tais sistemas, frequentemente, se sobrepõem e se cruzam, criando intersecções complexas nas quais dois, três ou quatro eixos se entrecruzam. As mulheres racializadas frequentemente estão posicionadas em um espaço onde o racismo ou a xenofobia, a classe e o gênero se encontram. Por consequência, estão sujeitas a serem atingidas pelo intenso fluxo de tráfego em todas essas vias" (CRENSHAW, 2002, p. 177).
}

Autoras ligadas a diferentes campos do feminismo afirmam que a interseccionalidade se tornou um hit concept ou um conceito mainstream, principalmente nos meios acadêmicos norte-americano e europeu, atingindo franco sucesso a partir dos anos 2000 (PISCITELLI, 2008; CARBIN; EDENHEIM, 2013; HIRATA, 2014; KERNER, 2016). No Brasil, o termo vem crescendo cada vez mais, ocupando prateleiras em livrarias (AKOTIRENE, 2018; ABREU; HIRATA; LOMBARDI, 2016) e figurando em cursos de pósgraduação e eventos acadêmicos.

Esse sucesso, contudo, se deu à custa de um afastamento entre o conceito e seu sentido original (e radical), ligado ao feminismo negro norte-americano. É o que apontam Sara Carbin e Maria Edenheim, pesquisadoras nórdicas de matriz teórica pósestruturalista. Carbin e Edenheim, ao analisarem o crescimento da interseccionalidade no contexto da pesquisa feminista europeia e norte-americana, trazem uma análise que consideramos bastante instigante. Elas argumentam que a "vitória" do termo tem relação com seu caráter "aberto", o que resultou na falta de discussões ontológicas importantes e permitiu que fosse adotado como uma espécie de linguagem universal que permitiria um consenso entre feministas de orientações políticas e teóricas conflitantes (CARBIN; EDENHEIM, 2013). Para as autoras, "a interseccionalidade [...] não preenche os

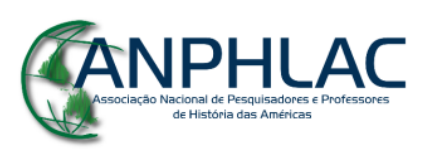


requerimentos de uma teoria e consequentemente 'todo mundo' sente que ela se adequa ao 'seu modo de pesquisar'" (CARBIN; EDENHEIM, 2013, p.13, tradução minha).

Ina Kerner (2016) também identifica uma mudança de caráter na interseccionalidade na medida em que foi ganhando espaço nos meios acadêmicos, deslocando-se das margens dos estudos feministas para seu centro. Segundo ela, o termo tem cada vez mais transcendido a orientação dada por sua origem, ligada às mulheres negras e "de cor", e se expandido como mecanismo de interpretação de questões variadas (para pensar abstratamente relações entre categorias de desigualdade, por exemplo) (KERNER, 2016). Kerner afirma que

\footnotetext{
"A metáfora da interseccionalidade pode facilmente ser destacada da crítica social radical do feminismo negro e de mulheres de cor, de onde precisamente a ideia de interseccionalidade surgiu. Nesse sentido, pode-se dizer que, ao menos em alguns casos, foi a metáfora e não a ideia que viajou com tanto sucesso das margens do feminismo para o centro dos estudos de gênero e das ciências sociais em geral" (KERNER, 2016, p. 15, tradução minha).
}

Diante do enevoamento de conflitos teóricos e políticos sob a metáfora da interseccionalidade e o esvaziamento da crítica política original do conceito, é premente voltar a atenção à proposta original de Kimberlé Crenshaw. A autora utiliza pela primeira vez o conceito no artigo "Demarginalizing the intersection of race and sex" (CRENSHAW, 1989), no qual explicita impasses jurídicos em que mulheres negras norte-americanas se encontraram como resultado de uma abordagem aditiva dos preconceitos racial e de gênero. No emblemático caso DeGraffernreid v. General Motors, esse grupo social se viu privado da garantia de seus direitos na medida em que o judiciário considerou que uma situação trabalhista que contemplou homens negros e mulheres brancas teria, consequentemente, contemplado a questão racial e de gênero, negligenciando a especificidade jurídica das mulheres negras. Contratar mulheres e contratar negros não significou a contratação de mulheres negras, mas a perspectiva aditiva do judiciário norteamericano naquele momento não garantia os direitos de um grupo social atingido pela interseção de racismo e sexismo. Diante desse quadro, Crenshaw advoga por uma perspectiva interseccional (CRENSHAW, 1989). A gênese da interseccionalidade, como

\section{GANPHLAC}


se pode ver, se dá a partir de uma demanda jurídica bastante prática: a exclusão de dado grupo social de direitos que deveriam estar garantidos a ele.

Concentrar-me-ei a seguir nos artigos "Mapping the margins: intersectionality, identity politics, and violence against women of color" (CRENSHAW, 1993), nos quais Crenshaw aprofunda suas considerações ao abordar as diferentes formas de violência contra mulheres de cor, e "Documento para o encontro de especialistas em aspectos da discriminação racial relativos ao gênero" (CRENSHAW, 2002), o primeiro texto da autora traduzido no Brasil, razão pela qual vem informando muitas/os pesquisadoras/es interessados em trabalhar com interseccionalidade no país.

Em "Mapping the margins", Crenshaw afirma que seu objetivo é "explorar as dimensões de raça e gênero da violência contra mulheres de cor" (CRENSHAW, 1993, p.1242, tradução minha). Nesse texto, ela retoma e aprofunda alguns aspectos de seu trabalho anterior (CRENSHAW, 1989), no qual refletiu sobre a influência da interseccionalidade nas configurações do mercado de trabalho, considerando as experiências de mulheres negras e de cor. Já o "Documento para o Encontro de Especialistas em Aspectos da Discriminação Racial Relativos ao Gênero" (CRENSHAW, 2002) se volta à intervenção em políticas de direitos humanos. Nesse texto, Crenshaw estabelece uma crítica ao universalismo que caracteriza a proteção dos direitos humanos das mulheres via Declaração Universal dos Direitos Humanos, argumentando que ele "fundamentava-se firmemente nas experiências dos homens" e que, por isso, não dava conta das experiências específicas e das violências sofridas por mulheres, escamoteadas como abusos "periféricos" (CRENSHAW, 2002 p.171-172). Ela assinala que um processo similar ocorre em torno da questão racial, já que a discriminação que não se enquadra em um modelo-padrão pode ser "tratada como 'excessivamente diferente' das experiências formais do tipo apartheid para que possa constituir abuso de direitos humanos" (CRENSHAW, 2002, p.172). Para alterar esse cenário, a autora propõe "um modelo provisório para a identificação das várias formas de subordinação que refletem os efeitos interativos das discriminações de raça e de gênero", além de sugerir "um protocolo provisório a ser seguido, a fim de melhor identificar as situações em que tal discriminação interativa possa ter ocorrido" (CRENSHAW, 2002, p.171, grifos meus).

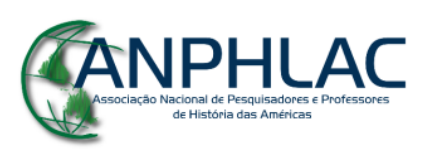


No texto de 1993, Crenshaw afirma que a interseccionalidade deve constituir "uma metodologia que irá, em última instância, interromper as tendências a ver raça e gênero como exclusivos ou separáveis", ressaltando também aqui seu caráter "provisório" (CRENSHAW, 1993, p.244, tradução minha, grifos meus). Ela divide a "metodologia" em três aspectos: "interseccionalidade estrutural", isto é, "as formas com que a localização das mulheres de cor na interseção de raça e gênero"; "interseccionalidade política", relativa à "política feminista e antirracista", ou seja, a esses movimentos sociais e suas ações e; "interseccionalidade representativa", referente à "construção cultural das mulheres de cor" (CRENSHAW, 1993, p.1245, tradução minha).

A interseccionalidade estrutural, com sua ênfase na "localização", pode ser relacionada à definição de interseccionalidade que aparece no "Documento...", citada anteriormente, que descreve a metáfora do cruzamento de diversas "avenidas" - os "eixos de poder". Ela chega a usar o termo "topologias" para se referir à localização de mulheres no entrecruzamento interseccional (CRENSHAW, 2002, p.177).

Nesse mesmo texto, Crenshaw elabora uma definição que resume bem sua proposta:

\footnotetext{
"A interseccionalidade é uma conceituação do problema que busca capturar as consequências estruturais e dinâmicas da interação entre dois ou mais eixos da subordinação. Ela trata especificamente da forma pela qual o racismo, o patriarcalismo, a opressão de classe e outros sistemas discriminatórios criam desigualdades básicas que estruturam as posições relativas de mulheres, raças, etnias, classes e outras" (CRENSHAW, 2002, p.177).
}

Essa definição é precedida por um subtítulo que a apresenta como uma "conceituação metafórica". "Conceituação metafórica", "modelo provisório", "protocolo provisório", "metodologia" etc.: a variedade de expressões associadas à interseccionalidade, bem como seu reafirmado aspecto provisório, pode ser relacionada ao caráter aberto que Carbin e Edenheim identificaram como tendo sido, por um lado, fonte de sucesso do conceito e, por outro, motivo de confusões teóricas e apropriações indevidas. $\mathrm{O}$ fato de o conceito englobar categorias que suscitam debates teóricos extensos e profundos, tais como raça, classe social, gênero e sexualidade, pode ter dado origem a um salto de compreensão que transforma a própria interseccionalidade em teoria




- algo que Crenshaw, ao menos segundo os textos analisados, não parece ter tido como pretensão.

Um ponto relevante é o fato de Crenshaw priorizar, dentre outras, as interseções entre raça e gênero. Em "Mapping the margins", ela procura demonstrar como as mulheres de cor não têm sido representadas pelo feminismo nem pelo antirracismo, sendo marginalizadas em ambos, e afirma que "as experiências das mulheres [que sofrem violência doméstica] são frequentemente o produto de padrões intersectados de racismo e sexismo" (CRENSHAW, 1993:1243, tradução minha). Uma nota de rodapé traz uma breve ressalva em relação à sua priorização. Nela, a autora explica que "o conceito pode e deve ser expandido ao trazer para a equação questões como classe, orientação sexual, idade e cor" (CRENSHAW, 1993, p.1244-1245, tradução minha).

Essa priorização de raça e gênero, em detrimento de classe e sexualidade, por exemplo, tem sido apontada por críticos da interseccionalidade como um de seus grandes problemas (HIRATA, 2014; FERGUSON, 2017). No artigo de 1993, a questão de classe é mencionada em termos de "opressão de classe" -- e não exploração -- quando Crenshaw se refere a mulheres "pobres", "desempregadas" e "subempregadas" (CRENSHAW, 1993, p.1245-46, tradução minha), ponto que não chega a desenvolver além da menção. ${ }^{5}$ Vale observar que o termo "pobres", usado para qualificar mulheres, revela uma abordagem quantitativa da classe - pobre sendo aquela que não possui dinheiro ou acesso ao consumo - em vez de uma concepção qualitativa, ligada à concepção de luta de classes.

A abordagem parcial ou periférica da classe social nos trabalhos que adotam a interseccionalidade como pressuposto é um elemento da crítica que tem sido estabelecida por autoras ligadas ao feminismo materialista francófono (HIRATA, 2014) e ao marxismo. Helena Hirata sistematiza alguma dessas críticas, em especial as feitas pela feminista materialista francesa Danièle Kergoat:

"1) a multiplicidade de pontos de entrada (casta, religião, etnia, nação etc., e não apenas raça, gênero e classe) leva a um perigo de fragmentação das práticas sociais e à dissolução da violência das relações sociais, com o risco de

\footnotetext{
${ }^{5}$ A palavra classe ("class") aparece também no início do texto, quando Crenshaw afirma que questões como a violência doméstica afetam as "mulheres enquanto classe" ("women as a class") (CRENSHAW, 1993, p.1241, tradução minha). Acredito que aqui a autora não utilize a palavra para se referir à classe social no sentido a que temos nos referido, mas provavelmente como grupo social de certo tipo.
}



Revista Eletrônica da ANPHLAC, ISSN 1679-1061, № 27, p.280 -309, Ago./Dez., 2019.

http://revista.anphlac.org.br 
contribuir à sua reprodução; 2) não é certo que todos esses pontos remetem a relações sociais e talvez não seja o caso de colocá-los todos num mesmo plano; 3) os teóricos da interseccionalidade continuam a raciocinar em termos de categorias e não de relações sociais, privilegiando uma ou outra categoria, como por exemplo a nação, a classe, a religião, o sexo, a casta etc., sem historicizá-las e por vezes não levando em conta as dimensões materiais da dominação.” (HIRATA, 2014, p.65)

Nesse mesmo sentido, a socióloga brasileira Heleieth Saffioti, que também teorizou sobre a relação necessária entre classe, gênero e raça nas relações sociais, defendia que "nem todos os fenômenos são da mesma natureza ou têm a mesma capacidade de determinação" (SAFFIOTI, 2001, p. 133). Para melhor compreender tais questões, pode-se considerar a crítica que muitos/as autores/as marxistas têm feito à noção de "identidade". Kenan Malik, em artigo sobre raça e pós-modernismo, reconhece a importância da percepção de que os seres humanos estão sujeitos a reivindicações e identidades conflitantes, mas argumenta que

\begin{abstract}
"O problema surge, contudo, quando todas as identidades são tratadas como equivalentes, de modo tal que preferências pessoas em estilo de vida, como os 'estilos musicais', recebem o mesmo peso e importância que atributos físicos, tais como 'deficiência física' ou alguns produtos sociais como raça e classe [...]. $\mathrm{Na}$ verdade, para começar, já há um problema quando se concebe raça ou classe como uma 'identidade'. Reações sociais, tal como opressão racial, não se transformam absolutamente em relações sociais, mas em atributos pessoais ou mesmo em opções de estilo de vida. Quando raça é considerada equivalente a 'estilos musicais' ou a códigos de vestuário', aparentemente o 'social' não significa nada mais que uma decisão particular que qualquer indivíduo pode tomar, e a 'sociedade' é reduzida ao agregado de identidades individuais" (MALIK, 1999, p.127).
\end{abstract}

Essa afiada crítica à ideia de identidade ressalta o perigo de compreender como individual um tipo de relação que é social, histórico e efetivamente material. O que Malik e Kergoat apontam é o caráter problemático de compreender que há tantas identidades quanto há possibilidades de estilos de vida disponíveis para escolha de cada indivíduo. Não é isso que está em jogo quando se pensa sistemas estruturantes das relações sociais. Embora a crítica de Kergoat se volte especificamente à interseccionalidade, não acredito que essa posição seja inerente ao conceito, mesmo porque a própria Kimberlé Crenshaw assinalou como parte de sua proposta o "processo de reconhecer como social e sistêmico

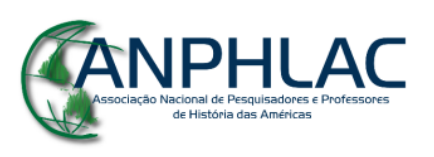


o que foi anteriormente percebido como isolado e individual" (CRENSHAW, 1993, p.124142, tradução minha).

Crenshaw utiliza a noção de identidade constantemente em seus escritos, adotando uma pluralidade terminológica para se referir a gênero, raça, classe etc., como "categorias identitárias" (CRENSHAW, 1993, p.1242, tradução minha), "padrões de subordinação" (CRENSHAW, 1993, p.1249, tradução minha), "múltiplas dimensões da identidade" (CRENSHAW, 1993, p.1299, tradução minha), "eixos de poder", "eixos de subordinação" (CRENSHAW, 2002, p.177), entre outros. Ela se refere a "grupos identitários" e "políticas identitárias" (CRENSHAW, 1993, p.1299, tradução minha), mas também fala em "sistemas de subordinação" e "estrutura" (CRENSHAW, 2002, p.176), termos que ressaltam mais o aspecto social e histórico das questões abordadas. O fato de a interseccionalidade, segundo sua proposta original, não constituir uma teoria não significa que não carregue consigo categorias que têm, por si só, carga teórica (gênero, classe, raça, etc.). Seria fundamental, então, explicitar a partir de que matriz teórica se abordam tais categorias, já que mencioná-las sem identificar esse aspecto fundamental tem gerado a falsa percepção da interseccionalidade como linguagem comum, quando na verdade há perspectivas diferentes e, com frequência, conflitantes em jogo.

Como foi dito, a relevância do conceito de interseccionalidade vai além do aspecto teórico-metodológico, sendo ele mesmo expressão e instrumento das lutas travadas por intelectuais negras dentro e fora dos meios acadêmicos nas Américas e no mundo. Diante de tais debates, a posição aqui defendida é a retomada da origem radical e antissistêmica da noção de articulação do feminismo negro, presente na declaração pioneira do Combahee River Collective:

"Reconhecemos que a libertação de todas as pessoas oprimidas requer a
destruição dos sistemas político-econômicos do capitalismo e do imperialismo,
tanto como a do patriarcado. Somos socialistas porque cremos que o trabalho
deve ser organizado para o benefício coletivo daqueles que o realizam e criam
os produtos, e não para o proveito dos patrões. Os recursos materiais têm de
ser distribuídos igualmente entre todos que os produzem. Não estamos
convencidas, entretanto, que uma revolução socialista que não seja também
uma revolução feminista e antirracista nos garantirá nossa libertação. [...]
Precisamos verbalizar a situação real de classe de pessoas que não são
simplesmente trabalhadoras sem raça, sem sexo, mas para quem as opressões
raciais são significantes determinantes em suas vidas de trabalho/econômicas.
Ainda que compartilhemos um acordo essencial com a teoria de Marx no que GANPHLAC 
se refere às relações econômicas específicas que ele analisou, sabemos que sua análise precisa se estender mais para que nós compreendamos nossa situação econômica específica como negras" (LA COLECTIVA DEL RIO COMBAHEE, 1988, p. 176, tradução minha).

A perda da dimensão da luta de classes no uso do conceito de classe social, transformado em mera descrição de quantidade de riqueza possuída e de acesso ao consumo, faz o jogo do liberalismo, matriz ideológica diametralmente oposta a um entendimento crítico da interseccionalidade. bell hooks explicou como "a ideologia do 'individualismo competitivo, atomista e liberal" chegou a permear o feminismo ao ponto de quase minar o radicalismo potencial da luta feminista (HOOKS, 1984: 7, tradução minha). Ela explica que

\begin{abstract}
"Mulheres que não se opunham ao patriarcado, ao capitalismo, ao classismo ou ao racismo se intitularam 'feministas'. [...] Queriam igualdade social em relação aos homens de sua classe; outras queriam pagamento igual para trabalhos iguais; outras queriam um estilo de vida alternativo. Muitas dessas preocupações legítimas foram facilmente cooptadas pelo patriarcado capitalista dominante" (HOOKS, 1984, p. 7, tradução minha).
\end{abstract}

Assim, hooks assinala que "a ordem burguesa, o capitalismo e o falocentrismo estão prontos para integrar quantas feministas forem necessárias" (FOUQUE apud HOOKS, 1984, p. 7, tradução minha). Nesse sentido, pode-se considerar que a análise interseccional que considera racismo e sexismo, mas que não desenvolve uma crítica do capitalismo, não representa uma ameaça real aos sistemas integrados que produzem desigualdade, já que as demandas individuais podem ser tragadas por ele sem custos significativos, mas as lutas coletivas exigem sua desestruturação.

A compreensão quanto à articulação dessas categorias se torna particularmente importante na análise as realidades latino-americanas e caribenhas, dado o papel fundamental do sexismo, da desigualdade de classes, do colonialismo e do racismo nesses contextos. É nesse sentido que Ochy Curiel, teórica feminista negra dominicana, argumenta que pensar raça, sexo, classe e sexualidade articuladamente

"nos dá ferramentas para entender por exemplo como a mestiçagem como ideologia nacionalista e homogeneizante teve como base fundamental a violação das mulheres indígenas e negras por parte dos colonizadores, a partir

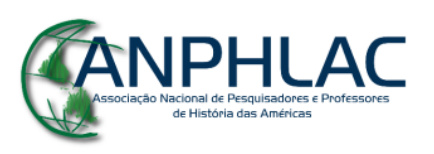


de uma lógica heterossexual que faz com que os homens se apropriem do corpo das mulheres, sobretudo aquelas cujos corpos são valorizados ou como mercadoria, ou como meros objetos referidos à natureza" (CURIEL, 2008, p. 20, tradução minha).

Curiel faz um esforço particular para compreender a questão da sexualidade nessa dinâmica. Em La Nación Heterosexual, a autora analisa a Constituição Colombiana de 1991 como um contrato que "expressa o regime da heterossexualidade na nação" (CURIEL, 2013, p. 29, tradução minha), ou seja, um "contrato heterossexual" (CURIEL, 2013, p. 42, tradução minha). De acordo com Curiel, a heterossexualidade "não se trata de uma prática social dentro de uma diversidade [de práticas]", mas de "uma instituição e um regime político que atravessa as relações sociais, afetando fundamentalmente às mulheres e às lésbicas" (CURIEL, 2013, p. 28, tradução minha). Apesar de não partilhar da maior parte das orientações teóricas da autora, concordamos com a importância de levar em conta o peso da sexualidade - em particular da heterossexualidade compulsória - nas relações sociais que formaram historicamente nações na América Latina e no Caribe que passaram pela experiência do colonialismo. Ao analisar o quadro histórico da colonização, ela retoma o papel central da mestiçagem na definição das identidades nacionais na América Latina e no Caribe, discussão que já travamos anteriormente para o caso brasileiro. Curiel cita a autora hondurenha Breny Mendoza, que introduz a heterossexualidade na análise da mestiçagem como dispositivo de poder na conformação da sociedade hondurenha. Para Mendoza, "o conceito de mestiçagem foi construído como uma categoria heterossexual, pois implicou o produto híbrido da relação entre o espanhol e a mulher indígena, através da apropriação de seus corpos, de sua sexualidade e de sua força de trabalho" (BRENY apud CURIEL, 2013, p. 146, tradução minha). Essa relação pode, sem dúvida, ser pensada para o caso brasileiro, principalmente os seguintes aspectos abordados por Mendoza: "a vinculação entre conquista, racismo e sexualidade, a partir da qual se explica a invasão dos corpos das mulheres, fundamentalmente através de atos de violação sexual" pelos colonizadores e seus descendentes; "o caráter heterossexual e o fator reprodutivo que regulam o regime de família patriarcal" (BRENY apud CURIEL, 2013, p. 145-146, tradução minha).

A filósofa Sueli Carneiro argumenta sobre a necessidade urgente de "enegrecer o feminismo" diante do apagamento das demandas políticas e da experiência histórica das

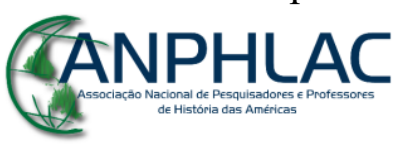


mulheres negras no "discurso clássico sobre a opressão da mulher" (CARNEIRO, 2011, s.p.). Ela observa o processo descrito por Curiel, acentuando o lugar da violência sexual como verdade ocultada pelo mito da democracia racial decorrente da miscigenação na América Latina, em especial no Brasil:

\begin{abstract}
"a violação colonial perpetrada pelos senhores brancos contra as mulheres negras e indígenas e a miscigenação daí resultante está na origem de todas as construções de nossa identidade nacional, estruturando o decantado mito da democracia racial latino-americana, que no Brasil chegou às últimas conseqüências. Essa violência sexual colonial é, também, o 'cimento' de todas as hierarquias de gênero e de raça presentes em nossas sociedades, configurando aquilo que Angela Gilliam define como 'a grande teoria do esperma em nossa formação nacional', através da qual, segundo Giliam: 'O papel da mulher negra é negado na formação da cultura nacional; a desigualdade entre homens e mulheres é erotizada; e a violência sexual contra as mulheres negras foi convertida em romance" (CARNEIRO, 2011, s.p.).
\end{abstract}

No caso do Brasil, "o estupro colonial da mulher negra pelo homem branco no passado e a miscigenação daí decorrente" não apenas constituíram base para o mito da democracia racial ${ }^{6}$, mas também para o "mito da cordialidade" brasileira ${ }^{7}$, desdobrandose em uma expressão do racismo que tem na negação uma de suas armas mais poderosas (CARNEIRO, 1995, p. 546). Uma pesquisa realizada no Brasil em 1988, citada por Lília Schwarcz em "Nem preto, nem branco, muito pelo contrário" (SCHWARCZ, 2013), indicou que $97 \%$ dos entrevistados disseram não serem racistas e $98 \%$ afirmaram conhecer quem fosse racista. O paradoxo representado pelos dados se tornou exemplo da negação e do silenciamento desse cruel racismo "à brasileira". Uma das principais intelectuais a

\footnotetext{
${ }^{6}$ Sobre o mito da democracia racial, Antonio Sérgio Guimarães destrincha suas origens e desdobramentos em "Democracia racial: o ideal, o pacto e o mito" (GUIMARÃES, 2002). Segundo o autor, ele se relaciona a uma ideia de que o Brasil seria uma "sociedade sem 'linha de cor", que deu origem à "construção mítica de uma sociedade sem preconceitos e discriminações raciais" (GUIMARÃES, 2002, p. 139). Embora não tenha usado a expressão, é atribuída a Gilberto Freyre a autoria da noção de "democracia racial" por ter sido "na sociologia moderna, [...] o primeiro a retomar a velha utopia do paraíso racial, cara ao senso comum dos abolicionistas, dando-lhe uma roupagem científica (GUIMARÃES, 2002, p. 149). O movimento de denunciar a "democracia racial" brasileira como um mito é feito pela resistência negra contra o "discurso estatal que impedia a organização das lutas anti-racistas" por meio da negação da existência de racismo no Brasil (GUIMARÃES, 2002, p. 158).

${ }^{7}$ Ao falar em mito da cordialidade, a autora de refere a um desdobramento do conceito de "homem cordial" brasileiro, de Sérgio Buarque de Hollanda, que deu base à ideia de que as relações sociais no Brasil são marcadas por cordialidade, harmonia e resolução de problemas através de relações personalistas (SOUZA, 2007).
}

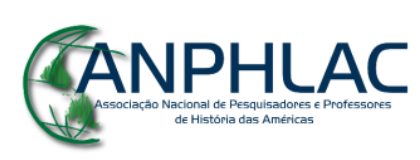


formular uma análise sobre essas relações no caso brasileiro foi Lélia Gonzalez, sobre cuja obra nos debruçaremos a seguir.

Nos textos produzidos por Gonzalez na década de 1970 e no início dos anos 1980, a autora demonstra uma significativa influência marxista, ainda que estabelecendo com essa matriz de pensamento um diálogo bastante crítico. Segundo Raquel Barreto, nesse momento ela "estava mais interessada em analisar e compreender a formação do capitalismo brasileiro com recorte racial" (BARRETO, 2018, p. 16). No decorrer dos anos 1980, as categorias marxistas de análise vão dando lugar a um diálogo com a psicanálise, com o feminismo e, principalmente, com uma perspectiva ligada ao afrocentrismo (BARRETO, 2018, p. 16). ${ }^{8}$

É possível relacionar o marxismo presente na obra de Gonzalez à perspectiva política original do Movimento Negro Unificado (MNU), do qual foi fundadora. O movimento demonstrava forte afinidade com uma perspectiva socialista de combate às diferentes formas de desigualdade social, defendendo a importância de uma solidariedade entre os grupos sociais oprimidos. A perspectiva de Gonzalez, nos textos escritos nos anos seguintes à fundação do MNU (1978), dedicou-se principalmente à caracterização do capitalismo brasileiro e a centralidade do racismo (primordialmente) e do sexismo em sua formação e sua dinâmica contemporânea. A autora faz referência e se posiciona quanto a temas na ordem do dia do pensamento social brasileiro àquela altura, como os debates sobre desenvolvimento e dependência e as peculiaridades da formação econômica brasileira, introduzindo também novas questões e perspectivas pioneiras de análise.

Examinando a produção intelectual sobre relações raciais no Brasil até o momento em que escrevia, Gonzalez identificou três tendências dominantes no âmbito da sociologia acadêmica. A primeira tendência seria aquela que trata a integração do negro como algo que viria a acontecer em decorrência da industrialização e da modernização

\footnotetext{
${ }^{8}$ Segundo Bussotti e Nhaueleque, o afrocentrismo é uma corrente filosófica que "pretende edificar um novo paradigma alternativo ao eurocêntrico dominante", propondo que a África não apenas é o "berço da humanidade", mas o "berço da civilização" a partir do Egito Antigo, tendo primazia nos "diferentes aspetos do saber: filosofia, ciência, religião, política, arte, comunicação" (BUSSOTTI; NHAUELEQUE, 2018, p. 1). Paulo Farias ressalta, contudo, que não é "uma doutrina monolítica, mas um rótulo que cobre um leque de posturas e propostas" (FARIAS, 2003, p. 317), um conjunto de ideias que possui uma longa genealogia e que "inclui tradições que reconciliam, de maneira aparentemente paradoxal, assimilação à chamada cultura ocidental com separação em relação a esta” (FARIAS, 2003, p. 318).
}

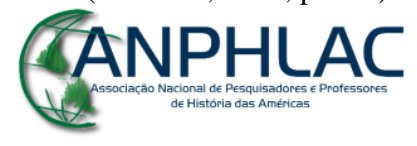


do país. Essa perspectiva analisaria o processo abolicionista sob uma ótica que vê no despreparo dos negros a justificativa para não terem assumido o papel de trabalhadores livres: "cultura da pobreza, anomia social, família desestruturada, explicariam as desigualdades raciais vigentes" (GONZALEZ, 2018e [1979], p. 62). Citando autores como Florestan Fernandes e Otávio Ianni como pertencentes a tal tendência, Gonzalez critica o fato de ela "deslocar para o negro as razões de sua mobilidade social", desconsiderar "o fato de que a grande maioria da população de cor (90\%) já se encontra livre e economicamente ativa antes de 1888 " e, finalmente, liberar "o segmento branco e suas instituições, em face da menor responsabilidade quanto à situação atual do negro" (GONZALEZ, 2018e [1979], p. 62).

A segunda tendência identificada por ela se localiza no que chama de "marxismo ortodoxo", cuja abordagem economicista diluiria a categoria "raça" ao argumentar que "a discriminação não passa de um instrumento manipulado pelo capitalista que visa [...] dividir o operariado. A solução seria a aliança entre trabalhadores de diferentes raças" (GONZALEZ, 2018e [1979], p. 62). Na crítica a essa tendência, a autora lembra a situação extrema da relação entre o operariado na África do Sul do apartheid, além de sublinhar a peculiaridade da realidade brasileira, em que "a maioria da população, praticamente, não alcançou a situação de força de trabalho relacionada ao capitalismo industrial competitivo" (GONZALEZ, 2018e [1979], p. 62).

A terceira abordagem identificada por Gonzalez "é aquela que [a]firma serem os grupos racialmente subordinados, minorias que internalizam o processo de colonização" (GONZALEZ, 2018e [1979], p. 63). O grande exemplo disso, segundo ela, é Oliveira Viana, mulato, pertencente a um "grupo racialmente dominado que internacionalizou e reproduziu a linguagem do grupo dominante", tendo sido "grande ideólogo do branqueamento da população brasileira" (GONZALEZ, 2018e [1979], p. 63).

Sua perspectiva particular se diferencia dessas três tendências, mas, segundo ela, leva em consideração as duas últimas em sua formulação. Sua análise do capitalismo brasileiro dialoga diretamente com os fervilhantes debates, à época, sobre dependência e desenvolvimento. Gonzalez se baseia largamente nas formulações do intelectual argentino José Nun e sua tese da "massa marginal" para argumentar quanto à existência no Brasil de um capitalismo desigual e dependente, cuja dinâmica externa de dependência

\section{GANPHLAC}


"neocolonial" resultaria em uma dinâmica interna de coexistência entre diferentes processos de acumulação: o capitalismo competitivo (comercial e industrial) e o capitalismo monopolista - este último, hegemônico.

Segundo essa perspectiva, configuram "massa marginal” desempregados, trabalhadores não-assalariados, trabalhadores que não possuem situação estável de assalariamento (p.e. prestadores de serviços domésticos), trabalhadores ocasionais, trabalhadores em atividades terciárias de baixa renda, etc. (FILHO; OLIVEIRA, 2012, p. 3; DELFINA, 2012, p. 25, tradução nossa). O cientista político brasileiro Lúcio Kowarick acrescenta ainda trabalhadores autônomos de comércio de mercadorias (ambulantes) e prestadores de serviços (FILHO; OLIVEIRA, 2012, p. 3).

A autora recupera a história da escravidão e da abolição para demonstrar de que forma a população negra ocupou o lugar de "massa marginal", argumentando que o processo de formação da figura do trabalhador livre típico do capitalismo no Brasil passou por "fatores deformadores", já que vínculos característicos de formas pré-capitalistas de mão-de-obra ainda se mantinham em grande parte no setor rural. Essas formas de trabalho se articulam "(em graus de maior ou menor complexidade) com o setor hegemônico da economia e de maneira proveitosa para este último" (GONZALEZ, 2018e [1980], p. 55). Dessa forma, Gonzalez se posiciona frontalmente contra a tese de que a discriminação racial consiste em uma sobrevivência de formações sociais anteriores, que viria a desaparecer progressivamente com o desenvolvimento do capitalismo. Ao contrário, ela procura demonstrar, ao levar à tese de Nun o impacto das relações raciais e de gênero, como esses fatores integram o capitalismo e o beneficiam.

Ao colocar o racismo no centro do debate, Gonzalez defende a existência de uma "divisão racial do trabalho" no Brasil. Com isso, ela pretende destacar a forma como a discriminação racial atravessa as diferentes classes sociais, fazendo com que o racismo beneficie não apenas a burguesia branca (a que ela se refere no trecho a seguir como “capitalismo branco"), mas também os trabalhadores brancos:

“O privilégio racial é uma característica marcante da sociedade brasileira, uma vez que o grupo branco é o grande beneficiário da exploração, especialmente da população negra. E não estamos nos referindo apenas ao capitalismo branco, mas também aos brancos sem propriedade dos meios de produção que recebem

\section{CANPHLAC}


os dividendos do racismo. Quando se trata de competir para o preenchimento de posições que implicam em recompensas materiais ou simbólicas, mesmo que os negros possuam a mesma capacitação, os resultados são sempre mais favoráveis aos competidores brancos. (GONZALEZ, 2018b [1979], p. 78)

Ao apontar para o fato de que os trabalhadores brancos recebem os "dividendos do racismo", Gonzalez sublinha a competição por recursos e posições escassos no capitalismo com a qual a classe trabalhadora se defronta. Esses "dividendos", que podem ser considerados benefícios em sentido imediato, em termos sistêmicos consistem em um reforço da alienação entre os sujeitos da classe trabalhadora, atuando na reprodução do sistema como um todo - e, assim, na reprodução das condições de exploração da classe trabalhadora. É nesse sentido que a autora afirma que

\begin{abstract}
"O racismo [...] denota sua eficácia estrutural na medida em que estabelece uma divisão racial do trabalho e é compartilhado por todas as formações capitalistas e multirraciais contemporâneas. Em termos de manutenção do equilíbrio do sistema como um todo, ele é um dos critérios de maior importância na articulação dos mecanismos de recrutamento para as posições na estrutura de classes e no sistema de estratificação social" (GONZALEZ, 2018d [1979], p. 98)
\end{abstract}

Se a reprodução sistêmica reforça os grilhões da classe trabalhadora como conjunto amplo, as condições objetivas impostas pelo racismo agravam em particular as vidas dos sujeitos negros. Gonzalez chama atenção para o lugar de tais sujeitos, em especial o das mulheres negras, no mercado de trabalho brasileiro, a despeito de se deparar com a "intenção [dos órgãos de pesquisa] de escamotear as informações a respeito da chamada população de 'cor' de nosso país" (GONZALEZ, 2018c [1981], p. 43). ${ }^{9}$ A população negra se encontrava principalmente no "desemprego aberto ou não, ocupação 'refúgio' em serviços puros, trabalho ocasional, ocupação intermitente ou por temporada" (GONZALEZ, 2018c [1981], p. 44) - justamente as atividades ocupadas pela "massa marginal", de José Nun. Um dos argumentos centrais de Gonzalez no período é justamente a caracterização da maioria da população negra como massa marginal, como consequência do desenvolvimento no Brasil de um capitalismo desigual e

\footnotetext{
${ }^{9}$ O censo dos anos 1970 excluiu o quesito "cor" e o de 1980 o incluiu como amostra, invisibilizando o fator racial nas informações demográficas do período (GONZALEZ, 2018c [1981], p. 43). Não por acaso, o período apontado pela autora é o do regime militar, que negava oficialmente a existência de racismo no Brasil e perseguia qualquer tipo de prática ou discurso que indicasse o contrário (KÖSSLING, 2007).
}

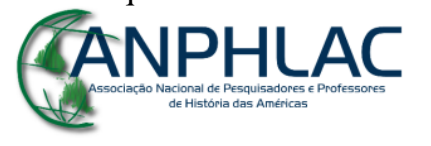

Revista Eletrônica da ANPHLAC, ISSN 1679-1061, № 27, p.280 -309, Ago./Dez., 2019.

http://revista.anphlac.org.br 
combinado/dependente (ela usa ambas as expressões), com hegemonia do capital monopolista.

As mulheres negras, nessa massa marginal, figuravam em atividades específicas como consequência das relações de gênero, além das de raça: atuavam "na prestação de serviços domésticos junto às famílias das classes média e alta" e "na prestação de serviços de baixa remuneração ('refúgios') nos supermercados, nas escolas ou nos hospitais sob a denominação genérica de "servente" (que se atente às significações que tal significante nos remete)" (GONZALEZ, 2018c [1981], p. 44-45). Embora Lélia tenha escrito em 1981, essa configuração se mostra atual em uma observação a olho nu das realidades brasileiras em zonas urbanas.

Um ponto interessante é a atenção que Gonzalez dá a uma ocupação específica: a "profissão" (gravada por ela entre aspas) de "mulata", em seus textos se referindo a mulheres negras passistas que trabalhavam em eventos relacionados a samba e carnaval. Nessa atividade, segundo a autora, jovens negras "submetem-se à exposição de seus corpos (com o mínimo de roupas possíveis), através do 'rebolado', para o deleite e voyeurismo dos turistas e dos representantes da burguesia nacional” (GONZALEZ, 2018c [1981], p. 46). Ela considera que essa profissão só pode ser exercida "num processo extremo de alienação imposto pelo sistema” às jovens negras, no qual

\footnotetext{
"sem se aperceberem, elas são manipuladas, não só como objetos sexuais, mas como provas concretas da 'democracia racial' brasileira; afinal, são tão bonitas e admiradas! Não se apercebem que constituem uma nova interpretação do velho ditado racista: "preta pra cozinhar/mulata pra fornicar/ e branca pra casar". Em outros termos, são sutilmente cooptadas pelo sistema sem se aperceberem do alto preço a pagar: o da própria dignidade" (GONZALEZ, 2018c [1981], p. 45-46)
}

Essa leitura tira o foco da agência ${ }^{10}$ das mulheres negras que atuam na profissão de "mulatas", na medida em que utiliza a concepção de alienação como "manipulação". Ela chega a se referir a um processo de "lavagem cerebral", argumentando que esse tipo de trabalho aparece como meio de ascensão social individual, como saída da pobreza,

\footnotetext{
${ }^{10}$ Agência aqui se apresenta no sentido marxista, em particular conforme usado por E.P. Thompson: traduzido do inglês "agency", o termo é "associado à noção de que os homens são sujeitos de sua própria história, embora em condições que não escolhem" (MATTOS, 2012, p. 27).
}

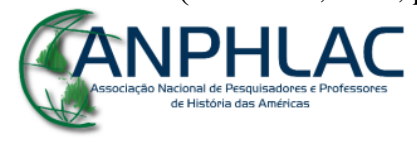


mas que na verdade levaria a maioria "à prostituição aberta, à bebida e outras drogas" (GONZALEZ, 2018c [1981], p. 46).

Sua interpretação quanto à mulata pode ser relacionada à sua concepção de racismo como "construção ideológica cujas práticas se concretizam nos diferentes processos de discriminação racial" (GONZALEZ, 2018c [1981], p. 41). Aqui, ideologia é categoria de Althusser, significando

\footnotetext{
"uma representação do real, mas necessariamente falseada, porque é necessariamente orientada e tendenciosa - e é tendenciosa porque seu objetivo não é dar aos homens o conhecimento objetivo do sistema social em que vivem, mas, ao contrário, oferecer-lhes uma representação mistificada deste sistema social, para mantê-los em seu "lugar", no sistema de exploração de classe" (ALTHUSSER apud GONZALEZ, 2018c [1981], p. 41)
}

Entender o racismo como ideologia no sentido althusseriano pode ser o que levou Gonzalez a usar noções de "manipulação" e "lavagem cerebral" para se referir a sujeitos negros que, em sua visão, de alguma forma fizeram o jogo do racismo. Essa perspectiva acaba por recair na "reificação da agência" denunciada por E. P. Thompson em referência à obra de Althusser (THOMPSON, 1981). Quando Gonzalez afirma a profissão da mulata como um "processo extremo de alienação", ela se refere muito mais à imposição de uma falsa consciência - a ideologia althusseriana -que efetivamente de uma dinâmica de alienação no sentido que encontramos em Marx.

Além de ter como base a discussão de José Nun para compreender a relação entre capitalismo e racismo no Brasil, Gonzalez traz também uma proposição de Carlos Hasenbalg, baseada em Nikos Poulantzas, para compreender de que forma raça e classe se relacionariam em termos de estratificação social. A autora explica que a base dessa proposição é a "distinção estabelecida por Poulantzas entre os dois aspectos da reprodução ampliada das classes sociais": primeiramente, a reprodução dos lugares das classes (o aspecto principal) e em segundo lugar, a reprodução dos atores e sua distribuição entre esses lugares (o aspecto subordinado) (GONZALEZ, 2018c [1981], p. 41). Para Hasenbalg, a raça se relacionaria ao segundo aspecto, domínio da "formaçãoqualificação-submissão" dos sujeitos (HASENBALG apud GONZALEZ, 2018c [1981], p. 42). Assumir essa proposição

\section{GANPHLAC}


“implica em que as minorias raciais não estão excluídas da estrutura de classes das sociedades multirraciais onde as relações de produção capitalistas [...] são as dominantes. Mais ainda, o racismo [...] é um dos principais determinantes da posição dos negros e não-brancos dentro das relações de produção e distribuição" (HASENBALG apud GONZALEZ, 2018c [1981], p. 42)

O racismo e o sexismo se transformam assim em "parte da estrutura objetiva das relações ideológicas e políticas do capitalismo, a reprodução da divisão racial (ou sexual) do trabalho" (HASENBALG apud GONZALEZ, 2018c [1981], p. 42). Essa interpretação quanto à forma como racismo, sexismo e capitalismo se relacionam é fundamental na medida em que aborda tais relações estruturalmente, mas ainda de forma "subordinada". A abordagem de Gonzalez, de fato, apresenta uma divisão entre o que é econômico (domínio para qual utiliza as formulações de Jose Nun) e o que é político e ideológico, o que pode ser lido como uma referência indireta à metáfora da base/superestrutura, bastante relevante no contexto acadêmico em que escrevia. Isso não significa, contudo, que a autora recaísse de forma alguma em um determinismo econômico, pois em seus textos fez fortes críticas a perspectivas economicistas e apontou para a relevância da discriminação racial e de gênero nas relações de produção, não indicando uma relação de via única de determinação da superestrutura pela base.

Como nos referimos anteriormente, no desenrolar dos anos 1980 os escritos de Gonzalez vão revelando uma maior aproximação com o afrocentrismo, a psicanálise e com o feminismo - este último em diálogo crítico. Ela passa progressivamente de uma análise do capitalismo centrada na questão racial para uma preocupação com a compreensão da relação entre racismo e sexismo na realidade social, defendendo a especificidade da situação e da experiência das mulheres negras no Brasil, bem como da discriminação por elas sofrida. Já na primeira fase de sua obra, a autora conclui que se trata de um "processo de tríplice discriminação [...] (enquanto raça, classe e sexo)" (GONZALEZ, 2018c [1981], p. 42).

Gonzalez apresenta uma visão qualitativamente diferente em "Racismo e sexismo na cultura brasileira", ainda que o texto tenha sido apresentado em 1980, época em que publicou os textos com que trabalhamos até aqui. Nesse artigo, a autora aborda o racismo e o sexismo como um "duplo fenômeno", afirmando que "o racismo se constitui como a




sintomática que caracteriza a neurose cultural brasileira" (GONZALEZ, 2018h [1980], p. 191). Essa afirmação aponta para a forte influência da psicanálise em sua abordagem, notadamente de textos de Freud e Lacan. O objetivo desse artigo, segundo a autora, é compreender quais processos determinaram o "discurso" do mito da democracia racial, por que teve tanta aceitação e divulgação, o que ele "oculta" e como a mulher negra é situada nele (GONZALEZ, 2018h [1980], p. 191). A aproximação com a psicanálise se evidencia no enfoque do mito da democracia racial como "discurso" e "sintoma" que "oculta" um problema mais profundo, da ordem da cultura.

A mudança na forma dos textos também é sensível: Gonzalez adota uma linguagem muito mais informal, carregada de gírias, expressões populares e um humor mordaz, o que torna a leitura do texto fluida e mesmo agradável. Segundo a leitura de Cláudia Pons Cardos, em textos como esse a autora traz uma linguagem "sem obediência às exigências e às regras da gramática normativa, mas que, no entanto, reflete o legado linguístico de culturas escravizadas" (CARDOSO, 2014, p. 996). Nesse texto específico, Gonzalez explica brevemente que sua experiência em eventos internacionais, a participação no MNU e no Grêmio Recreativo Arte Negra e Escola de Samba Quilombo ajudara a transformar sua visão na medida em que "começaram a se delinear, para nós, aquilo que se poderia chamar de contradições internas" (GONZALEZ, 2018h [1980], p. 192). Assim, "enquanto mulher negra, sentimos a necessidade de aprofundar nessa (sic) reflexão, em vez de continuarmos na reprodução e repetição de modelos que nos eram oferecidos pelo esforço de investigação das ciências sociais" (GONZALEZ, 2018h [1980], p. 192). Dessa forma, Gonzalez se afasta de modelos explicativos como o de Jose Nun para, com base no "suporte epistemológico" da psicanálise, buscar uma interpretação original sobre a articulação entre racismo e sexismo no Brasil que fosse além da "perspectiva sócio-econômica" (GONZALEZ, 2018h [1980], p. 192).

Para situar a mulher negra no "discurso" da democracia racial e entender os "efeitos violentos que a "articulação" entre racismo e sexismo produz sobre ela (GONZALEZ, 2018h [1980], p. 191), Gonzalez aprofunda uma discussão estabelecida nos textos anteriores sobre as representações da mulher negra como mulata, doméstica e "mãe preta”. Essa discussão aqui se dá com base em duas noções centrais: consciência e

\section{GANPHLAC}


memória. A primeira aparece em sentido que se pode relacionar com o de ideologia, conforme apareceu nos textos discutidos anteriormente: "Como consciência, a gente entende o lugar do desconhecimento, do encobrimento, da alienação, do esquecimento e até do saber. É por aí que o discurso ideológico se faz presente" (GONZALEZ, 2018h [1980], p. 194). Já a memória seria “o lugar do não-saber que conhece, esse lugar de inscrições que restituem uma história que não foi escrita, o lugar da emergência da verdade, dessa verdade que se estrutura como ficção" (GONZALEZ, 2018h [1980], p. 194). Considerando que Gonzalez tem como suporte epistemológico a psicanálise, essas conceituações podem ser aproximadas das categorias freudianas de ego e $i d$, sendo este último próximo à percepção de memória como um nível mais profundo, não consciente mas portador de algum tipo de verdade. O ego, a consciência, se relaciona ainda ao sentido althusseriano de ideologia como falsa consciência (FREUD, 1990). A autora explica que

\footnotetext{
"Na medida em que é o lugar da rejeição, consciência se expressa como discurso dominante (ou efeitos desse discurso) numa dada cultura, ocultando memória, mediante imposição do que ela, consciência, afirma como a verdade. Mas a memória tem suas astúcias, seu jogo de cintura: por isso, ela fala através das mancadas do discurso da consciência" (GONZALEZ, 2018h [1980], p. 194).
}

Essas "mancadas" da consciência revelando o nível mais profundo da memória, em Freud são os "atos falhos" (FREUD, 2014). Assim, o "jogo" da linguagem, que revela a "verdade" por meio dessas "mancadas" da consciência, é a chave para desvendar o que a ideologia (ou consciência) do racismo oculta a partir da reprodução do discurso do mito da democracia racial.

O trecho supracitado também evoca a influência de Franz Fanon no entendimento da autora das similaridades dos efeitos do racismo em diversos contextos da diáspora negra. De acordo com Cardoso, "um dos principais traços do pensamento de Fanon" identificável na obra de Gonzalez "diz respeito à abordagem dos danos psicológicos causados pela relação de dominação/exploração entre dominantes e dominados" (CARDOSO, 2014, p. 968). Cardoso afirma que o pensamento fanoniano sobre racismo,

\section{GANPHLAC}


assimilação e alienação foram fundamentais para a reflexão de Gonzalez sobre o mito da democracia racial brasileira, didaticamente sintetizado por ela neste trecho:

\footnotetext{
"Racismo? No Brasil? Quem foi que disse? Isso é coisa de americano. Aqui não tem diferença porque todo mundo é brasileiro acima de tudo, graças a Deus. Preto aqui é bem tratado, tem o mesmo direito que a gente tem. Tanto é que, quando se esforça, ele sobre na vida como qualquer um. Conheço um que é médico. Educadíssimo, culto, elegante e com umas feições tão finas... nem parece que é preto" (GONZALEZ, 2018h [1980], p. 194)
}

Esse mito, como dissemos, produz efeitos específicos sobre as mulheres negras, apreendidos por Gonzalez por meio da análise da linguagem e das representações. Seu argumento se centra na ideia de que "os termos mulata e doméstica são atribuições de um mesmo sujeito" (GONZALEZ, 2018h [1980], p. 196). Por um lado, “o rito carnavalesco" é o momento em que o mito da democracia racial "é atualizado com toda sua força simbólica", quando a mulher negra passa por um "endeusamento carnavalesco", transformando-se em rainha, transfigurando-se "na Cinderela do asfalto, adorada, desejada, devorada pelo olhar de príncipes altos e loiros, vindos de terras distantes só para vê-la" (GONZALEZ, 2018h [1980], p. 196). Por outro lado, no avesso do endeusamento está o "cotidiano dessa mulher, no momento em que ela se transfigura em empregada doméstica" (GONZALEZ, 2018h [1980], p. 196).

Ao relacionar essa configuração de discurso com a experiência da escravidão, Gonzalez encontra na figura da mucama o engendramento das representações da mulata do carnaval e da empregada doméstica. No dicionário Aurélio, a autora verifica que Mucama consta com sua origem linguística do quimbundo, significando "amásia escrava", ocultada entre parênteses fora da definição oficial do verbete. Há, segundo a autora, uma "neutralização", um "esvaziamento" do sentido original na medida em que o dicionário apenas marca a face do trabalho, ao definir mucama como "a escrava negra moça e de estimação que era escolhida para auxiliar nos serviços caseiros ou acompanhar pessoas da família e que por vezes era ama-de-leite" (DICIONÁRIO AURÉLIO apud GONZALEZ, 2018h [1980], p. 197). Essa descoberta feita por Gonzalez tem relação direta com a discussão que estabelecemos anteriormente sobre a dimensão da sexualidade (da heterossexualidade compulsória e da violência sexual) na experiência da escravidão

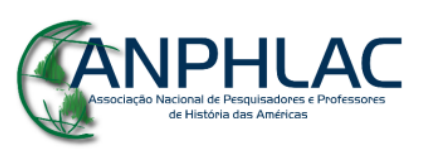


vivida pelas mulheres negras. O estupro colonial da mulher negra, para usar a expressão de Sueli Carneiro, que tem papel primordial na fundação do discurso da mestiçagem por toda América Latina, no caso brasileiro tem agravada a dimensão da ocultação, na qual mesmo o sentido ocultado - “amásia”, concubina, amante - não explicita a real dimensão de violência e agressão sofrida por essas mulheres.

A filósofa marxista Angela Davis, um dos maiores nomes do feminismo negro norte-americano, também voltou seu olhar à escravidão em "O legado da escravidão: parâmetros para uma nova condição da mulher". Nesse magistral texto de 1981, Davis critica a ausência de um estudo historiográfico que analisasse com seriedade a experiência das mulheres negras escravizadas nos Estados Unidos, apontando para a importância desse tipo de estudo não apenas "pela precisão histórica", mas porque traria "esclarecimentos sobre a luta atual das mulheres negras e de todas as mulheres em busca de emancipação" (DAVIS, 2016 [1981], p. 17). A partir de então, a autora desenvolve uma delicada análise baseada em fontes históricas e na bibliografia disponível sobre o assunto, enovelando representações culturais e condições objetivas estruturais, discussões sobre trabalho, gênero e violência, em um exemplo de abordagem qualitativa da articulação entre raça, classe, gênero e sexualidade. Um dos aspectos abordados por Davis é a violência sexual sofrida pelas escravas, analisada até então de maneira problemática. Os estudiosos do tema, elogiosos à ideia de miscigenação, apagavam o caráter de violência e de exploração sexual a despeito de que, na realidade, "dificilmente havia uma base para 'prazer, afeto e amor' quando os homens brancos, por sua posição econômica, tinham acesso ilimitado ao corpo das mulheres negras" (DAVIS, 2016 [1981], p. 38). Crítica similar é feita por Gonzalez a Caio Prado Jr., que objetificou e animalizou as mulheres escravizadas ao afirmar, por exemplo, que o "fator sexual" relativo a elas foi incapaz de realizar "o milagre do amor humano", que "constrói os edifícios de sentimentos os mais complexos e delicados" (PRADO JR. apud GONZALEZ, 2018h [1980], p. 199, 204).

Gonzalez encontra na figura da "mãe preta" a "única colher de chá" que Caio Prado Jr. dá na caracterização da população negra. Mas justamente essa questão "vai dar rasteira na raça dominante", na medida em que, no entendimento da autora, foi justamente a figura da mãe preta uma das responsáveis pelo fato de a cultura brasileira ser

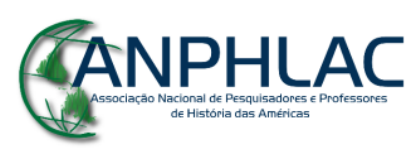


“eminentemente negra" (GONZALEZ, 2018c [1981], p. 41). A autora explica que a "figura da boa ama negra" (FREYRE apud GONZALEZ, 2018h [1981], p. 204) que consta em Caio Prado e Gilberto Freyre

\begin{abstract}
"não é esse exemplo extraordinário de amor e dedicação totais como querem os brancos e nem tampouco essa entreguista, essa traidora da raça como querem alguns negros apressados em seu julgamento. Ela, simplesmente é mãe. [...] Se assim não é, a gente pergunta: que[m] é que amamenta, que dá banho, que limpa cocô, que põe pra dormir, que acorda de noite prá cuidar, que ensina a falar, que conta história e por aí afora? É a mãe, não é? Ela é a mãe nesse barato doido da cultura brasileira. [...] A branca, a chamada legítima esposa, só serve prá parir os filhos do senhor. Não exerce a função materna" (GONZALEZ, 2018h [1981], p. 204-205).
\end{abstract}

A questão de Gonzalez, com essa afirmação, é apontar que a mãe preta, ao exercer a função de mãe, transmitiu uma série de valores às crianças brasileiras:

\begin{abstract}
"Ao nosso ver, a 'Mãe Preta' e o 'Pai João', com suas estórias, criaram uma espécie de 'romance familiar' que teve uma importância fundamental na formação dos valores e crenças do nosso povo, do nosso 'Volksgeist'. Conscientemente ou não, passaram para o brasileiro 'branco' as categorias das culturas africanas de quem eram representantes. Mais precisamente, coube à 'Mãe Preta' [...] a africanização do português falado no Brasil (o 'pretuguês', como dizem os africanos lusófonos) e, consequentemente, a própria africanização da cultura brasileira" (GONZALEZ, 2018c [1981], p. 40).
\end{abstract}

Essa conclusão é expandida por Gonzalez ao adotar o conceito de "amefricanidade" para caracterizar principalmente a América Latina, renomeada por M.D. Magno, autor no qual se baseia, como “Améfrica Ladina”. Essa nomeação procura negar a latinidade de matriz europeia e branca e, em contraponto, evidenciar a presença negra e a circularidade cultural de matriz africana pelas Américas (GONZALEZ, 2018a [1988], p. 321-322).

Nessas formulações de Gonzalez, a relação do Brasil e da América Latina com os países centrais, em particular os colonizadores, aparece principalmente em sua dimensão ideológica e cultural, com foco na dominação colonial. Afasta-se, portanto, de sua abordagem nos textos de fins dos anos 1970 e início dos 1980, quando sua abordagem se dava mais no sentido de compreender o desenvolvimento desigual e dependente/combinado do capitalismo e suas relações com o racismo e o sexismo. Aproxima-se, por outro lado, de autores como Franz Fanon, Molefi Asante e Walter

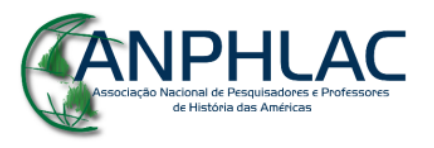


Rodney, lembrando ainda com admiração de Marcus Garvey - importantes intelectuais ligados a perspectivas afrocêntricas e pan-africanistas.

Em "Por um feminismo afrolatinoamericano", Gonzalez tem como objetivo contribuir para o avanço do feminismo latino-americano por meio da problematização de um esquecimento da questão racial nesse movimento, que ela considera como configurando "racismo por omissão", cujas raízes estão "em uma cosmovisão eurocêntrica e neocolonialista da realidade" (GONZALEZ, 2018g [1988], p. 309).

\begin{abstract}
"Tentar [compreender], por exemplo, a divisão sexual do trabalho sem articulá-lo com o correspondente ao nível racial é recair sobre um tipo de racionalismo universal abstrato, típico de um discurso masculinizante branco. Falar da opressão das mulheres latino-americanas é falar de uma generalidade que esconde, enfatiza, que tira de cena a dura realidade vivida por milhões de mulheres que pagam um preço muito alto por não serem brancas" (GONZALEZ, 2018g [1988], p. 310-311).
\end{abstract}

Nesse texto, a autora delineia o que ela vem chamando de "tripla discriminação", sintetizando as diversas discussões que estabeleceu em sua obra, inclusive quanto à questão de exploração do trabalho e do caráter dependente do capitalismo latinoamericano:

\footnotetext{
"No contexto das profundas desigualdades raciais existentes no continente, se insere de maneira muito bem articulada, a desigualdade sexual. Essa é uma dupla discriminação contra as mulheres não brancas na região: as mulheres africanas e ameríndias. O duplo caráter de sua condição biológica - ou racial e sexual - as torna as mulheres mais oprimidas e exploradas em uma região dependente de um capitalismo patriarcal e racista. Precisamente porque esse sistema transforma as diferenças em desigualdades, a discriminação que elas sofrem assume um caráter triplo, dada sua posição de classe: os ameríndios e afro-americanos fazem parte, em sua imensa maioria, do imenso proletariado latino-americano" (GONZALEZ, 2018g [1988], p. 314).
}

Neste artigo, procuramos delinear alguns aspectos fundamentais do pensamento de mulheres negras sobre a articulação entre gênero, raça, classe e sexualidade e, consequentemente, sobre suas formas de compreender a história e as relações sociais nas sociedades em que se inserem. Focamo-nos principalmente no conceito de interseccionalidade da jurista norte-americana Kimberlé Crenshaw, passando pelo pensamento de feministas latino-americanas como Ochy Curiel para chegarmos ao

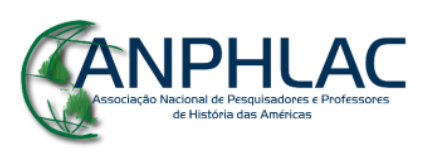


complexo pensamento social de Lélia Gonzalez. A despeito das substanciais diferenças entre suas proposições, o pensamento amefricano dessas autoras tem em comum um engajamento político comprometido com uma perspectiva contrária às opressões e formas de exploração presentes nas relações sócio-históricas das sociedades em que vivem. Isso se dá sob um ponto de vista que podemos chamar de "interseccional", na medida em que compreende as particularidades do racismo, do sexismo e do heterossexismo e das relações capitalistas, mas advoga principalmente por olhar a interrelação entre eles e seus efeitos. Com esse panorama, pretendemos sublinhar a importância do pensamento amefricano de mulheres não apenas como instrumentos de análise das questões ligadas ao sujeito coletivo "mulheres negras" nas Américas, mas como ferramentas de análise para a história das sociedades americanas de maneira global.

\section{Referências Bibliográficas}

ABREU, Alice Rangel de Paiva; HIRATA, Helena; LOMBARDI, Maria Rosa. Gênero e trabalho no Brasil e na França: perspectivas interseccionais. São Paulo: Boitempo, 2016.

AKOTIRENE, Carla. O que é interseccionalidade. Belo Horizone: Letramento / Justificando, 2018. Coleção Feminismos plurais.

BARRETO, Raquel. Lélia Gonzalez: uma intérprete do Brasil. In: GONZALEZ, Lélia. Primavera para as rosas negras: Lélia Gonzalez em primeira pessoa. São Paulo: Diáspora Africana, 2018.

CARBIN, Maria; EDENHEIM, Sara. The intersectional turn in feminist theory: a dream of a common language? European Journal of Women's Studies, pp. 1-16, 2013.

CARDOSO, Claudia Pons. Amefricanizando o feminismo: o pensamento de Lélia Gonzalez. Estudos Feministas, Florianópolis, v. 22, n. 3, p. 965-986, dez. 2014.

CARNEIRO, Sueli. Enegrecer o feminismo: a situação da mulher negra na América Latina a partir de uma perspectiva de gênero. Publicado em 06 de março de 2011. Disponível em <http://arquivo.geledes.org.br/em-debate/sueli-carneiro/17473-suelicarneiro-enegrecer-o-feminismo-a-situacao-da-mulher-negra-na-america-latina-a-partirde-uma-perspectiva-de-genero>. Acesso em 07 de setembro de 2015.

544-552, 1995.

Gênero, raça e ascensão social. Estudos feministas, Florianópolis, n. 2, p.

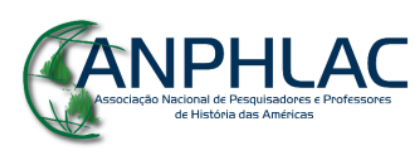

Revista Eletrônica da ANPHLAC, ISSN 1679-1061, № 27, p.280 -309, Ago./Dez., 2019.

http://revista.anphlac.org.br 
Popular / Fundação Perseu Abramo, 2017.

CRENSHAW, Kimberlé. Demarginalizing the Intersection of Race and Sex: A Black Feminist Critique of Antidiscrimination Doctrine, Feminist Theory and Antiracist Politics. University of Chicago Legal Forum, n. 1, p. 139-167, 1989.

Documento para o encontro de especialistas em aspectos da discriminação racial relativos ao gênero. Estudos Feministas, Florianópolis, v. 10, n. 1, pp. 171-188, 2002.

. Mapping the margins: intersectionality, identity politics, and violence against women of color. Stanford Law Review, vol. 43, p. 1241-1299, 1993.

CURIEL, Ochy. Género, Raza, Sexualidad: debates contemporaneos. 2008. Disponível em: $\quad<\mathrm{http}: / / w w w . u r o s a r i o . e d u . c o / u r o s a r i o \_f i l e s / 1 f / 1 f 1 d 1951-0 f 7 e-43 f f-819 f-$ dd05e5fed03c.pdf>. Acesso em: 29 jun. 2016.

La nación heterosexual: análisis del discurso jurídico y el régimen heterosexual desde la antropologia de la dominación. Bogotá: Brecha lésbica / em la frontera, 2013.

DAVIS, Angela. Mulheres, raça e classe. São Paulo: Boitempo, 2016.

DELFINO, Andrea. La noción de marginalidad em la teoria social latinoamericana: surgimiento y actualidad. Universitas Humanística, Bogotá, n. 74, p. 17-34, jul./dec. 2012.

FERGUSON, Susan. Feminismos interseccional e da reprodução social: rumo a uma ontologia integrativa. Cadernos Cemarx, n. 10, 2017, pp. 13-38.

FILHO, Carolina Figueiredo; OLIVEIRA, Nathalia C. Contribuições das teses marxistas da marginalidade para a análise das classes trabalhadoras e dos movimentos sociais. In: VII COLÓQUIO INTERNACIONAL MARX E ENGELS, 2012, Campinas, Anais... Campinas: CEMARX, 2012.

FREUD, Sigmund. O Ego e o Id. In: Edição standard brasileira das obras psicológicas completas de Sigmund Freud. v. 19. Rio de Janeiro: Imago, 1990.

Obras completas, volume 13: Conferências introdutórias à psicanálise. São Paulo: Companhia das Letras, 2014.

GONZALEZ, Lélia. A categoria Político-Cultural da Amefricanidade. In:

Primavera para as rosas negras: Lélia Gonzalez em primeira pessoa. São Paulo: Diáspora Africana, 2018a.

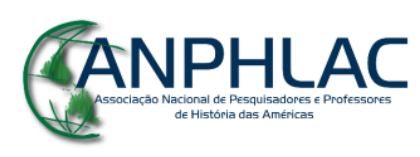

Revista Eletrônica da ANPHLAC, ISSN 1679-1061, № 27, p.280 -309, Ago./Dez., 2019.

http://revista.anphlac.org.br 
A Juventude Negra Brasileira. In: Primavera para as rosas negras: Lélia Gonzalez em primeira pessoa. São Paulo: Diáspora Africana, 2018b.

. A Mulher Negra na Sociedade Brasileira. In: . Primavera para as rosas negras: Lélia Gonzalez em primeira pessoa. São Paulo: Diáspora Africana, $2018 \mathrm{c}$.

A Questão Negra no Brasil. In: . Primavera para as rosas negras: Lélia Gonzalez em primeira pessoa. São Paulo: Diáspora Africana, 2018d.

Cultura, etnicidade e trabalho. In: . Primavera para as rosas negras: Lélia Gonzalez em primeira pessoa. São Paulo: Diáspora Africana, 2018e.

. Nanny. In: . Primavera para as rosas negras: Lélia Gonzalez em primeira pessoa. São Paulo: Diáspora Africana, $2018 \mathrm{f}$.

Por um Feminismo Afrolatinoamericano. In: Primavera para as rosas negras: Lélia Gonzalez em primeira pessoa. São Paulo: Diáspora Africana, $2018 \mathrm{~g}$.

Racismo e Sexismo na Cultura Brasileira. In: Primavera para as rosas negras: Lélia Gonzalez em primeira pessoa. São Paulo: Diáspora Africana, 2018h.

GUIMARÃES, Antonio Sérgio A. Classes, raças e democracia. São Paulo: FAPESP/Ed. 34, 2002.

HIRATA, Helena. Gênero, classe e raça: interseccionalidade e consubstancialidade das relações sociais. Tempo Social, v. 26, n. 1, p. 61-73, jun. 2014.

HOOKS, bell. Feminist theory: from margin to center. Boston: South end press, 1984.

KERNER, Ina. Relations of difference: power and inequality in intersectional and postcolonial feminist theories. Current Sociology, p. 1-21, 2016.

LA COLECTIVA DEL RIO COMBAHEE [COMBAHEE RIVER COLECTIVE]. "Una declaración feminista negra" [1977]. In: MORAGA, Cherríe; CASTILLO, Ana. Esta puente, mi espalda: voces de mujeres tercermundistas em los Estados Unidos. San Francisco: Ism Press, 1988.

LORDE, Audre. Sister outsider: essays and speeches by Audre Lorde. Berkeley: Crossing Press, 2007.

MALIK, Kenan. O espelho da raça: o pós-modernismo e a louvação da diferença. In: WOOD, Ellen M.; FOSTER, John B. Em defesa da história: Marxismo e pósmodernismo. Rio de Janeiro: Jorge Zahar Editor, 1999.

\section{CANPHLAC}

Revista Eletrônica da ANPHLAC, ISSN 1679-1061, № 27, p.280 -309, Ago./Dez., 2019.

http://revista.anphlac.org.br 
MATTOS, Marcelo Badaró. E. P. Thompson e a tradição de crítica ativa do materialismo histórico. Rio de Janeiro: Editora UFRJ, 2012.

PISCITELLI, Adriana G. Interseccionalidade, categorias de articulação e experiências de migrantes brasileiras. Sociedade e Cultura, v. 11, n. 2, jul./dez. 2008, pp. 263-274.

SCHWARCZ, Lília Moritz. Nem preto nem branco, muito pelo contrário: cor e raça na sociabilidade brasileira. São Paulo: Companhia das Letras, 2013.

SOUZA, Ricardo Luiz de. As raízes e o futuro do "Homem Cordial" segundo Sérgio Buarque de Holanda. Cadernos CRH, Salvador, v. 20, n. 50, p. 343-353, ago. 2007.

THOMPSON, Edward P. A Miséria da Teoria ou um planetário de erros: uma crítica ao pensamento de Althusser. Rio de Janeiro: Zahar, 1981.

\section{GANPHLAC}

